\title{
Correlation of financial burden with severity of asthma in children
}

\author{
Lahiri K. ${ }^{1}$, Najmuddin F. ${ }^{2}$ \\ ${ }^{1}$ Dr. Keya Lahiri, Professor, ${ }^{2}$ Dr. Fehmida Najmuddin, Assistant Professor, both authors are affiliated with Department of \\ Pediatrics, Dr. D.Y. Patil Medical College \& Hospital, Nerul, Navi Mumbai, Maharashtra, India.
}

Corresponding Author: Dr. Fehmida Najmuddin, Department of Paediatrics, Dr. D.Y. Patil Medical College \& Hospital, Nerul, Sector-5, Navi Mumbai, 400706, Maharashtra, India. Phone No: 09920030533, Email: fehmidanc9@gmail.com

\begin{abstract}
Introduction: Urbanisation is causing a rise in the financial burden of Asthma in children and it varies with the disease severity. Asthma has a low public health priority and is often under diagnosed and treated inappropriately. Objectives: Our aim was to correlate the financial burden of disease costs with Asthma classification. Methods: It was a prospective study of 38 patients attending paediatric pulmonology clinic in a tertiary care hospital. Details were entered in a predesigned proforma and institutional ethics committee approval was taken. Quantitative statistical analysis using mean, standard deviation and applying one way ANNOVA test was done. Results: Intermittent, mild and moderate persistent asthma were $8(21.05 \%), 21(55.26 \%)$ and $9(23.68 \%)$ respectively. Majority of the patients; $19(50 \%)$ belonged to the upper middle class. The direct mean costs across severities ranged between INR 5700-7400 for general practitioner consultation, INR 3550-10300 for emergency visits, INR 4500-9000 for investigations and INR 7000-13700 for medications. The indirect costs ranged between INR 9000-19800 on daily wages lost, INR 2900-8700 on travel expenses (significant $\mathrm{p}$ value $<0.014$ ) between mild and moderate persistent asthma. Mean costs on food ranged between INR 1700-3200, tuitions INR 3000-5700 and miscellaneous expenditure being INR 2000-8300. The percentage of annual income spent was $28.76 \%, 40.99 \%$ and $60.64 \%$ in intermittent, mild and moderate persistent asthma respectively. Conclusion: Early referral, diligent counselling, physician and parents education along with good compliance would impart effective control and thereby reduce economic burden.
\end{abstract}

Key words: Asthma, Economic burden, India, Paediatrics

\section{Introduction}

Paediatric asthma has emerged as the most common non-communicable cause of heightened morbidities. Increasing prevalence coupled with urbanisation in paediatric asthma has escalated the financial burden $[1,2]$. The current literature on financial impact of paediatric asthma in India is lacking and hence a diligent review system has to be devised for an effective reduction in the overall costs [3].

The lack of supporting data from developing countries on the financial burden of asthma compelled us to highlight the disease burden in our paediatric pulmonology out- patient department [4]. The disability - adjusted life years (DALYS) per year due to asthma is 13.8 million as per the world health organisation [5]. Paediatric asthma is one of the major reasons for school absenteeism which in turn increases the indirect costs [6]. In comparison to the adult asthmatics, expenses

Manuscript received: $18^{\text {th }}$ April 2018

Reviewed: $28^{\text {th }}$ April 2018

Author Corrected: $5^{\text {th }}$ May 2018

Accepted for Publication: $9^{\text {th }}$ May 2018 associated in paediatric asthma is higher due to lack of physician and parents awareness, misclassification, use of antibiotics and increased visits to day care centres $[7,8]$. The importance of research on the economic burden of asthma, comes from the fact that, though there is increased prevalence in developed countries, the developing countries account for $80 \%$ of asthma deaths worldwide [9]. Studies done across various states in India, itself have shown higher rate of prevalence in some compared to the others, therefore we need to study the financial impact area wise to devise an effective state appropriate budget [10]. As compared to the normal population, asthmatic individuals are twice more prone to develop poor physical and mental health each year, thereby adding on to their individual financial costs [11].

\section{Methods and Materials}

Aims and objectives: To correlate the financial burden of the disease costs with asthma classification. 


\section{Editorial}

Place and Type of study: It was a prospective study of 38 patients; 25 (65.8\%) males and 13(34.2\%) females attending paediatric pulmonology clinic in a tertiary care hospital.

Sample collection: Details were entered in a predesigned proforma, informed consent was taken and information including their personal information, classification of asthma according to GINA (Global Initiative Of Asthma) guidelines and current therapy was noted. Further the questionnaire included direct (general practitioner consultation, emergency visits investigations medications) and indirect costs (travel, food expenses, tuitions, daily wages loss, miscellaneous). An institutional ethics committee approval of our hospital was taken.

Sampling method: Quantitative statistical analysis using mean, standard deviation and one-way ANNOVA test was done.

Inclusion Criteria: Children with Asthma and Parents/ Care takers on regular follow-up. Exclusion criteria: Parents / care- givers not consenting to the study and asthmatic children not compliant or on regular follow-up.

\section{Results}

The study comprised of 38 patients; 25(65.8\%) males and $13(34.2 \%)$ females. Intermittent, mild and moderate persistent asthma were $8(21.05 \%), 21(55.26 \%)$ and $9(23.68 \%)$ respectively (Fig.1). The asthma classification was as per the GINA guidelines. Majority of the patients $19(50 \%)$ belonged to the upper middle class. The direct mean costs across severities ranged between INR 5700-7400 for general practitioner consultation, INR 3550-10300 for emergency visits (Fig.2), INR 4500-9000 for investigations and INR 7000-13700 for medications. The indirect costs ranged between INR 9000-19800 on daily wages lost, INR 2900-8700 on travel expenses (significant $p$ value $<0.014$ ) between mild and moderate persistent asthma. Mean costs on food ranged between INR 1700-3200, tuitions INR 3000-5700 and miscellaneous expenditure being INR 2000-8300. The economic impact progressively increased depending on the asthma classification. The percentage of annual income spent was $28.76 \%, 40.99 \%$ and $60.64 \%$ in intermittent, mild and moderate persistent asthma respectively.

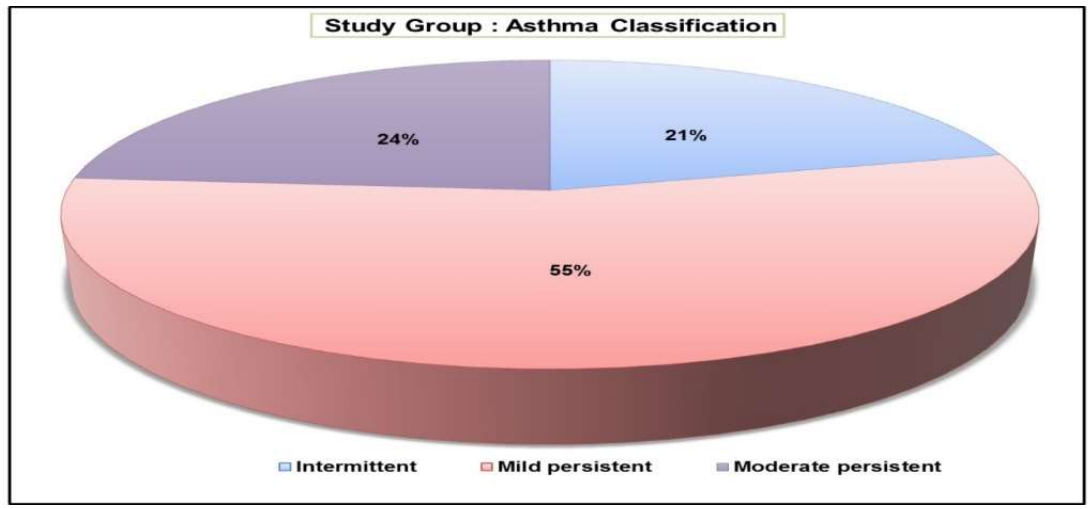

Figure- 1: Asthma classification according to GINA guidelines

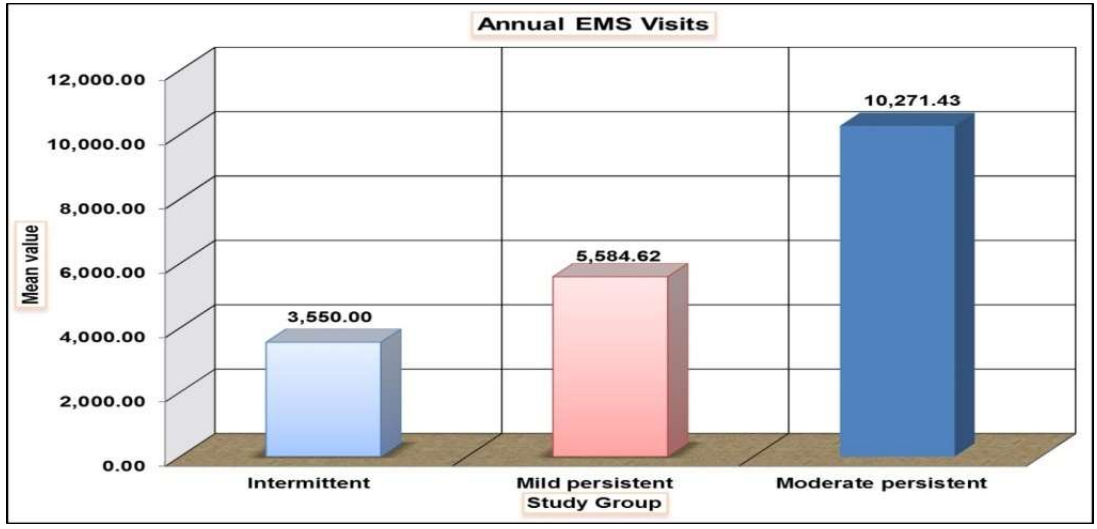

Figure-2: Expenditure on annual emergency visits 
Editorial

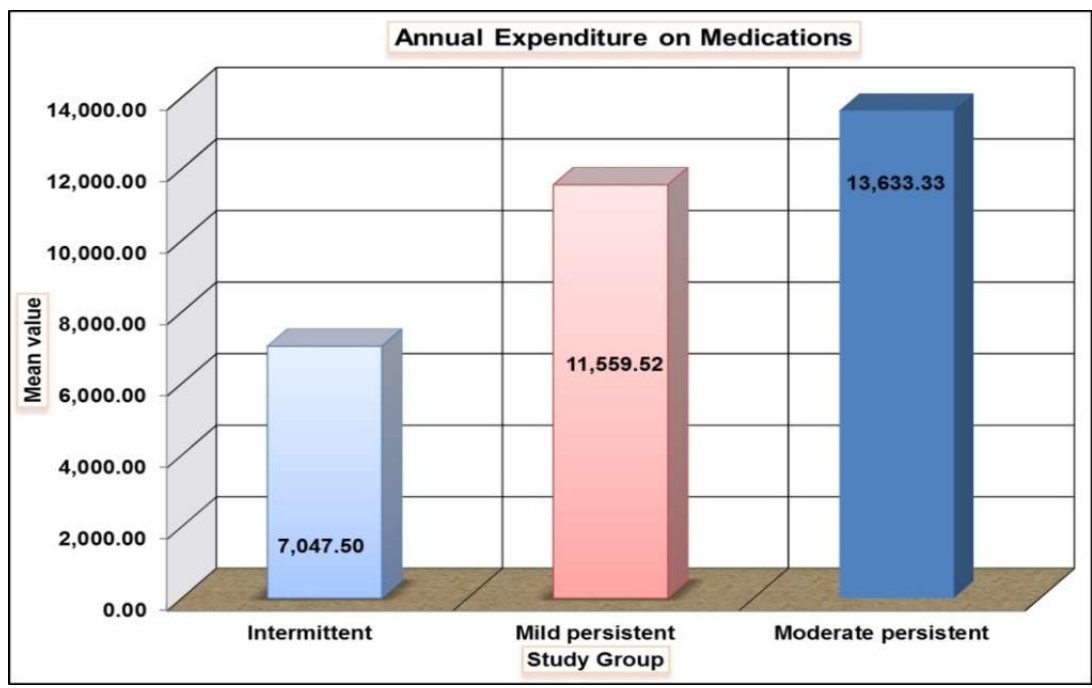

Figure-3: Graph showing the annual expenditure on medications

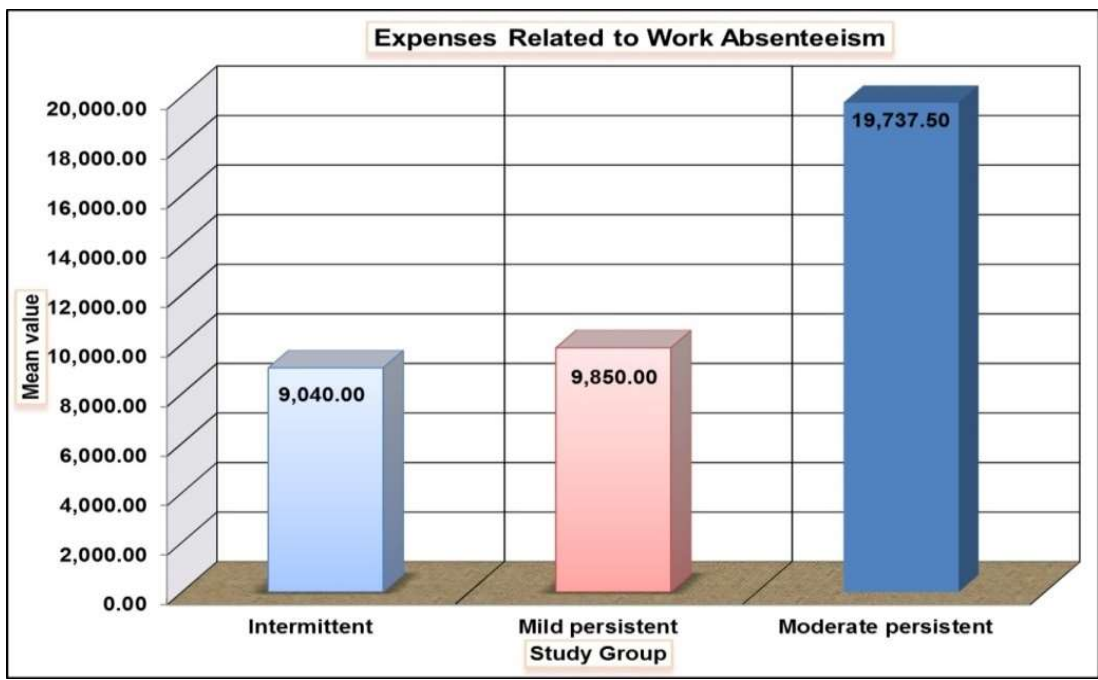

Figure-4: Expenses Incurred due to daily wages loss

\section{Discussion}

The economic burden of paediatric asthma has been sparsely studied in India. The direct costs mainly involved expenditure on medications (INR 7000-13700) (Fig. 3) which is similar to a study conducted wherein the drug costs form the majority of direct expenses [12]. Emergency Visits accounted for the second highest aspect of direct costs, which was higher compared tostudies done in Iran and other countries [13,14].

These expenses could be curtailed by proper classification, early intervention, appropriate inhalation therapies and instructions to the parents/ caretakers in the event of an exacerbation at home and during commuting [15]. The indirect costs accounted for a large portion of the expenditure as compared to direct costs, the main component being loss incurred in daily wages (INR 9000-19800) (Fig.4). Majority of the population belonged to the middle class, where income is dependent on daily earnings. In contrast, few high quality studies have shown a substantial portion of their expenditure incurred on direct costs [16,17]. A significant observation on indirect costs of patient shaving to travel distances ( $\mathrm{p}$ value $<0.014$ ) emphasises the need for primary asthma health care centres in order to facilitate and enhance prompt management of exacerbations. Our study revealed that direct and indirect costs were directly proportional to the grade of asthma $[18,19]$.

The importance of having a health insurance coverage should be emphasized, as none of ourpatients were enrolled under any health scheme. 


\section{Conclusion}

Institution of guidelines by the health care providers in the peripheral districts and cities would ensure reduction of the disease burden and better quality of life. It is pertinent to maintain an annual database in India, for effective strategies to be adopted in reducing the burden of paediatric asthma [20]. Paediatric asthma has a very good prognosis and effective counselling and preventative therapies would certainly reduce the overall burden in the country.

The Authors have no, real or perceived conflicts of interest that relate to this article.

The Authors have no source of financial support

\section{Author Contributions}

Conceptualization: Dr. Fehmida Najmuddin, Dr. Keya Lahiri

Data Curation: Dr. Fehmida Najmuddin

Formal Analysis: Dr. Fehmida Najmuddin

Methodology: Dr. Keya Lahiri

Supervision: Dr. Keya Lahiri

Validation: Dr. Keya Lahiri, Dr Fehmida Najmuddin

Writing, Review \& Editing: Dr. Keya Lahiri, Dr. Fehmida Najmuddin.

Funding: Nil, Conflict of interest: None initiated, Perission from IRB: Yes

\section{References}

1. Bousquet J, Knani J, Dhivert H, Richard A, Chicoye A, Ware JE Jr, et al. Quality of life in asthma. I. Internal consistency and validity of the SF-36 questionnaire. Am J Respir Crit Care Med. 1994 Feb;149 (2 Pt 1):371-5.

2. Riccioni G, D'Orazio N, Di Ilio C, Menna V, Guagnano MT, Della Vecchia R. Quality of Life and clinical symptoms in asthmatic subjects. J Asthma. 2004 Feb; 41 (1): 85-9.

3. Gergen PJ: Understanding the economic burden of asthma. J Allergy ClinImmunol2001.107(5):5445-5448.

4. Braman SS. The global burden of asthma. Chest. 2006 Jul;130(1 Suppl): 4S-12S.

5. Vos T, Flaxman AD, Naghavi M, Lozano R et al. Years lived with disability (YLDs) for 1160 sequelae of 289 diseases and injuries 1990-2010: a systematic analysis for the Global Burden of Disease Study 2010. Lancet. 2012 Dec 15; 380 (9859): 2163-96. doi: 10.1016/ S0140-6736 (12) 61729-2.
6. Fowler MG, Davenport MG, Garg R. School functioning of US children with asthma. Pediatrics.1992 Dec; 90 (6): 939-44.

7. Grupp-Phelan J, Lozano P, Fishman P. Health care utilization and cost in children with asthma and selected comorbidities. J Asthma. 2001 Jun;38(4):363-73.

8. Gupta RS, Bewtra M, Prosser LA, Finkelstein JA. Predictors of hospital charges for children admitted with asthma. Ambul Pediatr. 2006 Jan-Feb; 6(1):15-20.

9. Agrawal S, Pearce N, Ebrahim S. Prevalence and risk factors for self-reported asthma in an adult Indian population: a cross-sectional survey. Int J Tuberc Lung Dis. 2013 Feb;17(2):275-82. doi: 10.5588/ijtld.12.0438.

10. Agnihotram R, and Chattopadhyay A. Respiratory Disease Burden In Rural India:A Review From Multiple Data Sources, Internet J. Epidemiol, 2005; vol 2, no.2.

11. Ford ES, Mannino DM, Homa DM, Gwynn C, Redd SC, Moriarty DG, et al. Self-reported asthma and health-related quality of life: findings from the behavioral risk factor surveillance system. Chest. 2003 Jan; 123(1):119-27.

12. Bahadori K, Doyle-Waters MM, Marra C, Lynd L, Alasaly K, Swiston J, et al. Economic burden of asthma: a systematic review. BMC Pulm Med. 2009 May 19;9:24. doi: 10.1186/1471-2466-9-24.

13. Sharifi L, Dashti R, Pourpak Z, Fazlollahi MR, Movahedi M, Chavoshzadeh Z, et al. Economic Burden of Pediatric Asthma: Annual Cost of Disease in Iran. Iran J Public Health. 2018 Feb;47(2):256-263.

14. Dashti R, Sedighy M, Pourpak Z, Ahmadiani MS, Fazlollahi MR, Bavarian B, et al. Direct economic cost of acute asthma in emergency department. Indian J Pediatr. 2013 Aug;80(8):708-9. doi: 10.1007/s12098012 - 0912-8. Epub 2012 Nov 24.

15. Kauppi P, Linna M, Martikainen J, Mäkelä MJ, Haahtela T. Follow-up of the Finnish Asthma Programme 2000-2010: reduction of hospital burden needs riskgroup rethinking.Thorax. 2013Mar;68(3):2923.doi:10.1136/thoraxjnl-2011-201028.Epub2012Apr 15.

16. Wang LY, Zhong Y, Wheeler L. Direct and indirect costs of asthma in school-age children. Prev Chronic Dis. 2005 Jan; 2 (1):A11. Epub 2004 Dec 15. 


\section{Editorial}

17. Cisternas MG, Blanc PD, Yen IH, Katz PP, Earnest $\mathrm{G}$, Eisner MD, et al. A comprehensive study of the direct and indirect costs of adult asthma. J Allergy Clin Immunol. 2003 Jun;111(6):1212-8.

18. Ungar WJ, Coyte PC; Pharmacy Medication Monitoring Program Advisory Board. Prospective study of the patient-level cost of asthma care in children. Pediatr Pulmonol. 2001 Aug; 32 (2):101-8.
19. Shafazand S, Colice G.Asthma: the epidemic has ended, or has it? Chest. 2004 Jun;125(6):1969-70.

20. Matricardi PM, Bonini S. Why is the incidence of asthma increasing? In: Johnston SL, Holgate ST(eds). Asthma: Critical Debates. London: Blackwell Science; 2002: 3-17.

\section{How to cite this article?}

Lahiri K, Najmuddin F. Correlation of financial burden with severity of asthma in children. Int J Pediatr Res. 2018;5(5):273-277.doi:10.17511/ijpr.2018.i05.06. 